\title{
Numerical Simulation on Influence Factors of Aerodynamic Mistuning of Wind Turbine
}

\author{
Chen Xiaoming \\ North China Electric Power University \\ Key Laboratory of CMCPPE Ministry of Education \\ Beijing, China \\ e-mail: 44490178@qq.com
}

\author{
Kang Shun \\ North China Electric Power University \\ Key Laboratory of CMCPPE Ministry of Education \\ Beijing, China \\ e-mail: kangs@ncepu.edu.cn
}

\begin{abstract}
Wind turbine aerodynamic-mistuning phenomenon during the operation may cause great harm. This article is based on sliding mesh technique of three dimensional Unsteady CFD method,taking NREL Phase VI wind turbine as an example,study the pneumatic performance of wind turbine under the axial-flow condition ,and compare with the experimental data.After validate the accuracy of the method,according to the effect of yaw and wind shear on the wind turbine aerodynamicmistuning, researched have been conducted: In a wind shear condition,the aerodynamic performance after the blade rotating one circle have been calculated in the different wind profile index.Because of the shear wind velocity, Airfoil load and flow parameters fluctuate approximately like the patterm of cyclical cosine function with the change of azimuth.And with wind profiles index and spanwise position increases, impulse amplitudes have been also increased; Under the circumstances of the constant wind speed and variable yaw angle, The aerodynamic power decreases with the increase of the yaw angle There are also some big differences at different azimuth angle of blade section.
\end{abstract}

Keywords-yaw;aerodynamic;mistuning;shear;wind turbine

\section{INTRODUCTION}

Wind farms are locally clustered groups of wind turbines in the same location used to produce electric power. There are many advantages to this commercial structure $^{[1]}$. In 2020 horizontal-axis wind turbines (HAWTs) will reach 1 billion kilowatts ${ }^{[2]}$. Meanwhile, the wind turbine design and aerodynamic analysis are based on coordinated rotor system (a tuned system). Rotor is considered to be symmetric structure, each blade on the rotor structure properties, the same uniform to hit the flow under the condition of the same aerodynamic force ${ }^{[3-8]}$. However, in the real wind field in the process of the wind turbine operation, often will encounter all sorts of complex wind conditions, considering the wind shear, yaw and gust uneven to factors such as flow, or due to the difference of geometric shape flow around the blade has the difference, lead to the aerodynamic force and moment of blade by different ${ }^{[5]}$, these are called aerodynamic mistuning. For megawatt wind turbine the large scale rotor blades, aerodynamic mistuning will be more serious. So the study of aerodynamic mistuning has very important significance.

The flow in wind turbines, even in very large ones, is still essentially incompressible, with Mach numbers based on blade tip speed rarely exceeding 0.25 . This fact justifies the use of incompressible fluid solvers for most wind turbines. Methods of various levels of complexity to predict the aerodynamic behaviour of a wind turbine rotor have been developed. Nowadays, aerodynamic analysis of HAWTs are more popular in numerical methods. Using the Navier-Stokes equations (N-S equations), Duque ${ }^{[9]}$ obtained the pressure of a blade surface, which coincided fairly well with the experiment results. Meanwhile, Voutsinas $^{[10]}$ focused on the flow field under yaw using the CFD method. $\mathrm{Xu}$ and Sankar ${ }^{[11,12]}$ also proposed a promising method that involved solving the N-S equation by the CFD approach in a small area around the turbine blade and by vortex theory in the other areas. The results have provided lots of references for the design and operation of HAWTs.

This article will use the URANS method, threedimensional unsteady numerical simulation and verification in NREL Phase VI HAWT as the object, and will explore three-dimensional unsteady flow around characteristics of wind turbines under the conditions of yaw and wind shear, and analysed in detail.

\section{DESCRIPTION OF THE NUMERICAL EXAMPLE}

The objective of the present research effort is to validate a first-principles-based approach for modelling HAWTs under yawed flow conditions using NREL Phase VI rotor data ${ }^{[13-16]}$.

\section{MATHEMATICAL AND NUMERICAL METHODS}

The commercial software Fluent is adopted to improve the Reynolds-averaged Navier-Stokes equation (RANS) and unsteady Reynolds-averaged Navier-Stokes equation (URANS) calculation. For the unsteady calculation, the software adopts the dual time-step approach to solve the URANS and the time integration method of the Krylovtype methods. This research uses a Spalart-Allmaras turbulence equation model. In the three-dimensional model of the unsteady calculation, the physical time step adopted corresponds to an angle of $9^{\circ}$.

A rectangular calculation domain is built with a computational domain size of $18 \mathrm{R} \times 6 \mathrm{R} \times 6 \mathrm{R}$, the domain consists of two parts, namely the moving parts (cylinder and rectangle part) and the stationary part (wind tunnel part). The wind turbine is placed approximately in the middle of the moving parts, which are a $15.1 \mathrm{~m}$ (3R) diameter circle with a length of $5.03 \mathrm{~m}$ (1R) in the stream-wise direction. 
A grid with a total of 6.3 million elements in the computational domain was modelled by the Fluent software package under the ICEM born 1.3 million grid, rotating domain automatically by the NUMECA software package under the grid mesh generator AutoGrid5 B2B CUT function for 5 million grid, as shown in Figure 1 (a), which illustrates the distribution of the grid computational and rotating domains, while Figure 1 (b) illustrates a near blade for $\mathrm{O} 4 \mathrm{H}$ grid topology, which shows the grid number 101, blade exhibition to the grid width to 2000, nearly wall grid height $0.05 \mathrm{~mm}$, wall below average y + 10 , which meets the needs of the turbulence model.

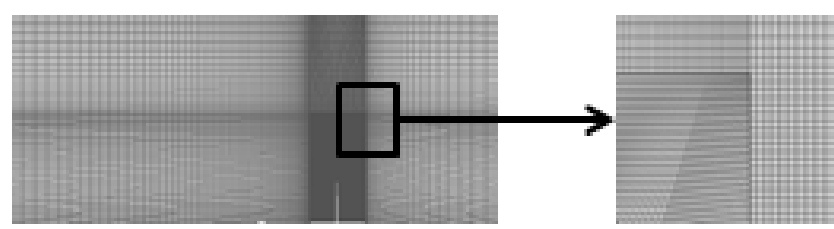

(a)

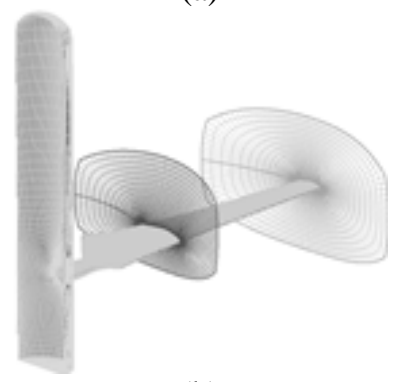

(b)

Figure 1. Meshing of three-dimensional model

Calculation domain inlet boundary given wind speed and air temperature; Set the boundary as pressure far-field outlet and calculating outside the border; Airfoil surface for the no slip boundary. Grid computing set rotation field is rotating, the grid computing domain is stationary, and the sliding mesh method is adopted for stator domain interface data transfer. The unsteady calculation parameters of the residual fell by more than four orders of magnitude, and the overall performance parameters achieved stability. The unsteady calculation performance parameters showed periodic changes.

\section{AERODYNAMIC CHARACTERISTICS UNDER THE CONDITION OF AERODYNAMIC MISTUNING}

CFD calculation results with experimental values under the condition of axial flow are shown in Figures 2 and 3. The results show that the power is well near experimental value at $7 \mathrm{~m} / \mathrm{s}$, the tangential force coefficient and normal force coefficient distribution of each section are in line with CFD calculation value and experimental value, proving that this method of CFD analysis is reasonable and reliable. On the basis of this, the calculation of yaw and wind shear was carried out.

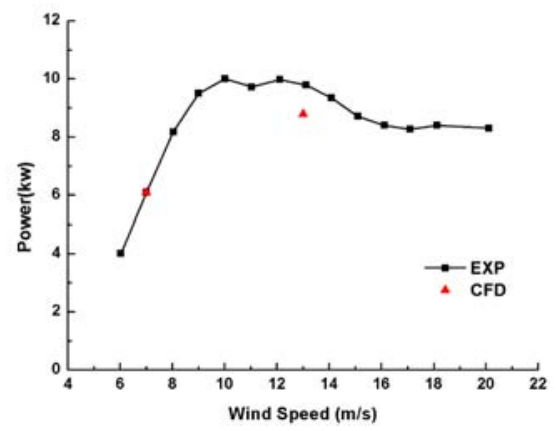

Figure 2. Aerodynamic power curves changes in wind speed

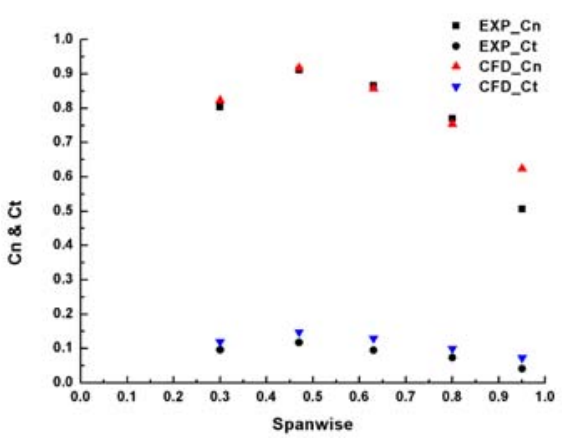

Figure 3. Changes in tangential force coefficient and normal force coefficient along the spanwise at $7 \mathrm{~m} / \mathrm{s}$

\section{A. Wind Shear}

Figure4 shows aerodynamic characteristics of airfoil under different wind speed profile index with a circle at $80 \%$ with exhibition location. The load bearing between the maximum and minimum difference is not consistent: along with the increase of wind speed profile index, to $80 \%$ in the quasi three dimensional model show nearly symmetric on aerodynamic characteristics of the fluctuations in a circle.

Figure5 shows wind shear under the airfoil aerodynamic characteristics of periodic fluctuation amplitude with the exhibition to the location and the change of wind speed profile index. The figure shows that the same exhibition to location airfoil fluctuation amplitude increases with the increase of wind speed profile index. Under the same wind speed profile index, due to the outside of the wings revolving wind speed fluctuation is bigger, causes the quasi three dimensional model of wave amplitude along the exhibition to increase. Under the condition of different wind speed profile index, the shear velocity in airfoil load and flow parameters along with the azimuth approximate cosine function of periodic fluctuation, fluctuation amplitude varies with wind speed profile index and exhibition to the position. 

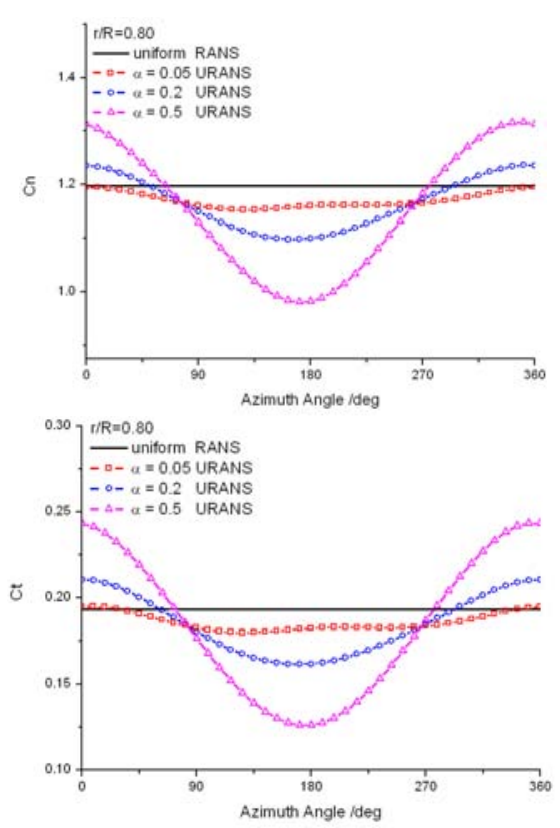

Figure 4. Aerodynamic characteristics of airfoil under different wind speed profile index with a circle (hub wind speed $8.6 \mathrm{~m} / \mathrm{s}, \mathrm{r} / \mathrm{R}=0.80$ )
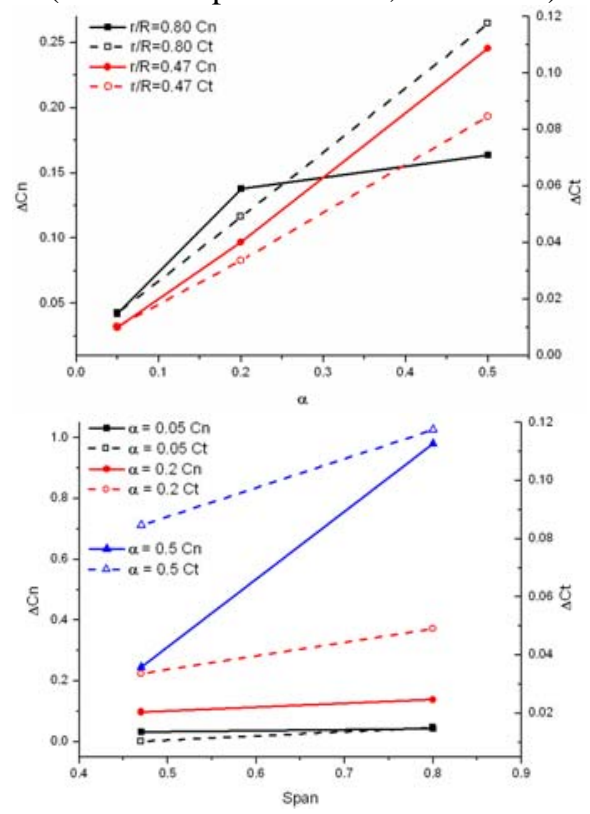

Figure 5. Aerodynamic characteristics of wave amplitude and exhibition to the distribution with the wind speed profile index

\section{B. Yaw}

Figure6 shows the torque load with yaw angle ,it can be seen that the torque is in decline along with the change of yaw angle, and in $10^{\circ}$ to $60^{\circ}$ the rate of torque change is nearly linear. So Torque varies with the yaw angle, and it is more sensitive at the yaw angle less than 10 degree than at the yaw angle between 10 degree and 60 degree.

Yaw flow direction is along the $\mathrm{z}$ axial partial $\mathrm{x}$ positive angle to 30 degrees as shown in Figure7, shows a comparison of limiting streamlines at the different direction angles and different sections between yaw flow and uniform flow. It shows that under the circumstance of the constant yaw angle, the attach angle reached its peak at 0 degrees azimuth, corresponding to the largest separation zone, and the attach angle hit the bottom at the direction of 180 degrees azimuth with the smallest separation zone. Because of the same attach angle between 90 and 270 degrees azimuth, the positions of the separation line are very similar. Noticeable changes are also found in the blade root separation zone position, with the corresponding limiting streamline also being affected. From the qualitative analysis of the flow pressure distribution at the $30 \%$ section, there is an obvious change in different yaw angle, while qualitative analysis of other sections does not see a very obvious change. We can infer that 0 degrees azimuth is more sensitive to separation.
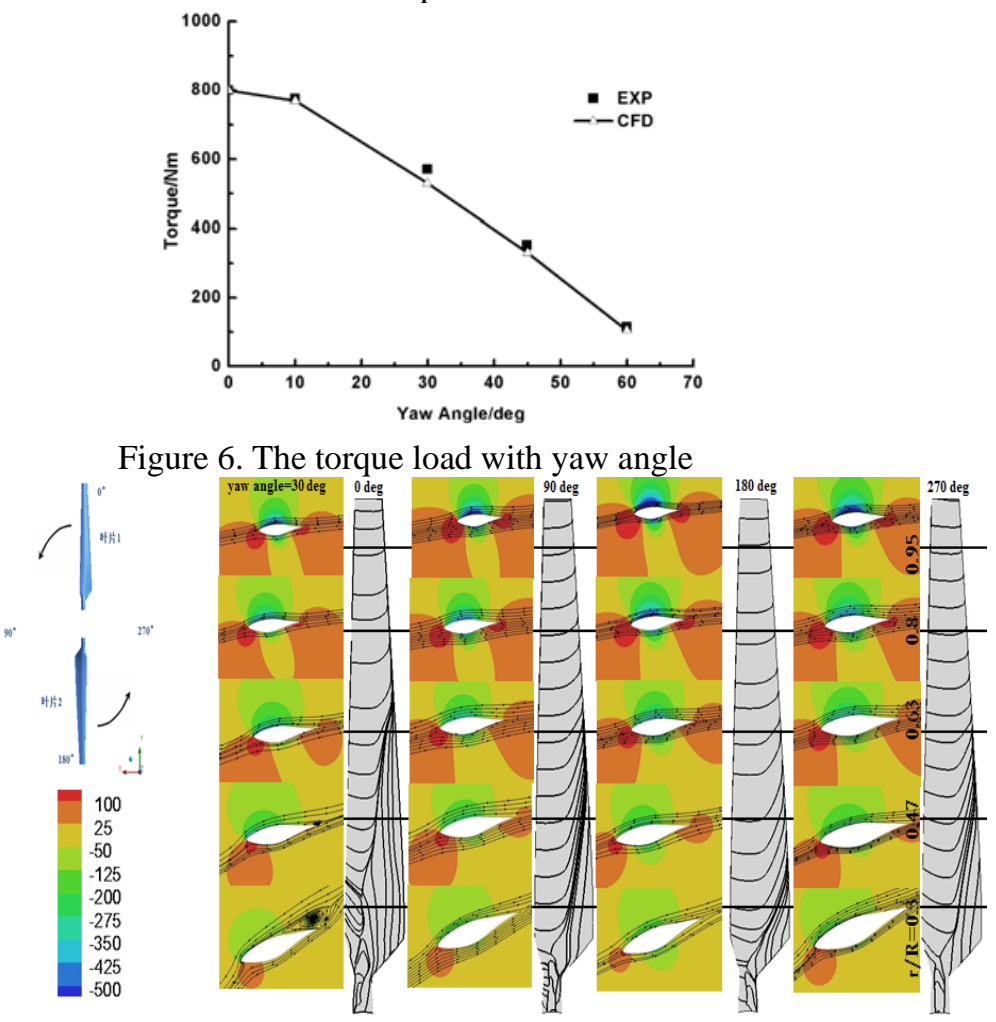

Figure 7. Pressure distribution at different sections and the streamline of blade at different angles at $7 \mathrm{~m} / \mathrm{s}$ and $30^{\circ}$ yaw angle

\section{CONCLUSIONS}

This paper established a three-dimensional unsteady CFD calculation method simulating wind turbine aerodynamic performance under yaw conditions, and the NREL Phase VI wind turbine is verified as an example. The conclusions drawn are as follows:

1. Under the condition of axial flow always, the study of wind turbine aerodynamic performance in the blade boundary layer shows no separation or separation of smaller exhibition to the position of section well reflect the aerodynamic characteristics.

2.In a wind shear condition, the aerodynamic perform ance after the blade rotating one circle have been calculate $\mathrm{d}$ in the different wind profile index, with wind profiles in dex and spanwise position increases, impulse amplitudes have been also increased

3. Under yaw condition, unsteady process is possible to see an obvious periodicity. With azimuth variation ,separation conditions are very different . Torque varies with the yaw angle, and it is more sensitive at the 
yaw angle less than 10 degree than at the yaw angle between 10 degree to 60 degree; 0 degree azimuth angle is more sensitive to separation.

\section{ACKNOWLEDGEMENTS}

The research work was supported by National Natural Science Foundation of China (No.51176046) and the National 863 high technology research and development plan project (2012AA051303).

\section{REFERENCES}

[1] Archer CL. Evaluation of global wind power. Journal of Geophysical Research 2005;110:D12110.

[2] Global Wind Energy Council. Global Wind Report-Annual market update 2010[R]

[3] Hand M, Simms D, Fingersh L, et al. Unsteady Aerodynamics Experiment Phase VI: Wind Tunnel Test Configurations and Available Data Campaigns Technical Report NREL/TP -50029955. NREL, 2001.

[4] Langtry R B.A Correlation-Based Transition Model using Local Variables for Unstructured Parallelized CFD codes. PhD thesis, Stuttgart, 2006.

[5] Hansena M O L, S Sensena J N, Voutsinasb S, et al. State of the Art in Wind Turbine Aerodynamics and Aeroelasticity. Progress in Aerospace Sciences, 2006, 42: 285-330.

[6] Anders A. Aeroelastic Simulation of Wind Turbine Dynamics. Royal Institute of Technology Department of Mechanics, 2005.

[7] Rachid Y, Ismail E B and Jeur-Bernard T, et al. Dynamic Study of a Wind Turbine Blade with Horizontal Axis. Eur. J. Mech. A/Solids, 2001,20: 241-252.
[8] Scott L and Mike Z, et al. Swept Wind Turbine Blade Aeroelastic Modeling for Loads and Dynamic Behavior. Larwood/Zuteck Wind power, 2006.

[9] E. P. N. Duque, C. P. Van Dam. Navier-Stokes simulation of the NREL combined experiment Phase II rotor[C]. Reno : 34th AIAA Aerospace Sciences Meeting. 1999.

[10] S. G. Voutsinas, J. P. Glekas, A. Zervos. Investigation of the effect of the initial velocity profile on the wake development of a wind turbine $[\mathrm{J}]$. Journal of Wind Engineering and Industrial Aerodynamics, 1992, 39(1-3) : 293-301.

[11] G. Xu, L. N. Sankar. Computational study of horizontal axis wind turbines[J]. Journal of Solar Energy Engineering, 2000, 122(1) : 35-39.

[12] G . Xu,L . N . Sankar . Application of a viscous flow methodology to the NREL Phase VI rotor[C]. ASME Conference Proceedings, 2002, 2002(7476X) : 83-93.

[13] Hand M, Simms D, Fingersh L, etc. Unsteady Aerodynamics Experiment Phase VI: Wind Tunnel Test Configurations and Available Data Campaigns [R]. NREL/TP-500-29955, NREL, 2001

[14] Simms, D. A., Schreck, S., Hand, M. M., and Fingersh, L. J, 2001 "NREL Unsteady Aerodynamics Experiment in the NASA-Ames Wind Tunnel: A Comparison of Predictions to Measurements," NICH Report No. TP-500-29494.

[15] Fingersh, L. J., Simms, D. A., Hand, M. M., Jager, D. W., Cotrell, J. R.,Robinson, M., Schreck, S. and Larwood, S. M., 2001, "Wind Tunnel Testing of NREL's Unsteady Aerodynamics Experiment,” AIAA Pap. 2001-0035.

[16] Giguere, P., and Selig, M., 1999, "Design of a Tapered and Twisted Blade for the NREL Combined Experiment Rotor," National Renewable Energy Laboratory,NREL/SR-500-26173, Golden, CO. 